\title{
Relationship between Safety Climate Factors and Safety Performance among the Workers in Cold Storage Industries
}

\author{
Rusli Ahmad ${ }^{1}$, Chang Li Ching ${ }^{2}$, Nur Fatihah Abdullah Bandar ${ }^{3 *}$, Hana Hamidi ${ }^{4}$, Ahmad Sofian Shminan $^{5}$, \\ Heng Chin Siong ${ }^{6}$
}

${ }^{1}$ Professor, Program of Human Resource Development, Faculty of Cognitive Sciences \& Human Development, UNIMAS, MALAYSIA

${ }^{2}$ Program of Human Resource Development, Faculty of Cognitive Sciences \& Human Development, UNIMAS, MALAYSIA

${ }^{3}$ Senior Lecturer, Program of Human Resource Development, Faculty of Cognitive Sciences \& Human Development, UNIMAS, MALAYSIA

${ }^{4,6}$ Lecturer, Human Resource Development, Faculty of Cognitive Sciences \& Human Development, UNIMAS, MALAYSIA

${ }^{5}$ Lecturer, Cognitive Sciences, Faculty of Cognitive Sciences \& Human Development, UNIMAS, MALAYSIA

*E-mail for correspondence: abnfatihah@unimas.my

\begin{abstract}
This study aims to determine the relationship between the safety climate factors (positive workforce safety attitude, acceptance of safety rules and regulation and reasonable production schedule) towards safety performance among workers who work under the cold storage company at Kuching, Sarawak, Malaysia. A survey methodology was used in this study. This research involves the utilization of questionnaire which was administered among one-hundred and fifty workers. The relationship between the safety climate factors (Positive workforce safety attitude, acceptance of safety rules and regulation and reasonable production schedule) were analyzed using the Pearson's Correlation analysis test. The results of this study revealed that there is a significant relationship between (positive workforce safety attitude and acceptance of safety rules and regulation) and safety performance. Meanwhile, result showed that there is no significant relationship between reasonable production schedule and safety performance. Hence, this study hoped to raise the awareness of organization about the importance of safety climate in the workplace.
\end{abstract}

Keywords: Cold storage industries, safety climate factors, safety performance

\section{INTRODUCTION}

This study investigates the relationship between safety climate factors and safety performance among workers at cold storage industries, Kuching, Sarawak, Malaysia. There are many factors that can lead to the occurrence of accidents in the workplace. Safety climate is one of the important contributing factors towards the safety performance in the workplace. Generally, the safety climate can change due to factors like changes in time, equipment, time management, and behavior. The safety climate should be taken into account from many perspectives so that the employer and employee will have a good relationship with each other (Zahoor, et al., 2015). The good relationship will lead to the safety performance in the workplace.

In every organization, safety always plays the main role to ensure everything is operating well. The safety climate is important to ensure the safety of every employee in the organization. Based on Hon, et al., (2014), the actual priority of safety in a workplace is reflexed by the safety climate of the organization. Safety climate is also important to improve the healthy working style and working environment (Kamarulzaman et al., 2011). Employees tend to work better in a satisfying working environment in the workplace (Dole and Schroeder, 2001). Therefore, it is important to investigate the relationship between safety climate and safety performance in the organization.

There is evidence proving that strong safety climate can lead to a higher safety performance. For example, in a report that prepared by Tharaldsen et al., (2008), it has mentioned that there is a significant inverse correlation between safety climate perceptions and accident rates in the offshore industry. Besides that, Mearns et al., (2003) also mentioned that an effective safety climate will lower the proportion of self-reported accidents in the offshore industry. The safety performance is positive when there is 
an increase in the safety climate. The increase of safety climate in the workplace is more likely to improve the performance of managers and employees in preventing accidents to occur during at work (Omogoroye and Oke, 2007).

\section{StATEMENT OF Problem}

From the theoretical point of view, Bigelow (2011) stated that safety climate has great potential in preventing and reducing accidents or injuries in the workplace. This is because it can help to increase the health and safety performance in the company. Dov (2010) indicated that the employees, the safety scheduling and the skills applied in the workplace play an important role in the safety climate in manufacturing field. The safety climate in the workplace can be influenced by these three factors. However, he claims that different type of field has a different perception of the safety climate and safety performance. Besides those three factors, Glendon and Mckenna (2000) stated that workforce attitudes can also be one of the measurements of safety culture and safety climate in the organization. This is because the attitudes are related to the safe and unsafe behavior. In order to reduce the incidents in the workplace, the employer plays a major role in providing safety equipment for their employees (Frank and Donald, 2010).

For empirical discussion, the previous research focused more on construction industry rather than the output industry. According to Zahoor et al., (2015), there is the significant relationship between safety climate and the increase of safety job performance in the construction research of multi-storey buildings. Based on Hon et al., (2014), safety climate measurement needs to be formulated by future research to investigate the three factors which are positive workforce safety attitude, acceptance of safety rules and regulation, and reasonable production schedule within the organization in another field. The behavior and working environment contribute to the safety performance in the workplace but there is the limited study of the behavior factor in output industry (Zin and Ismail, 2011). Employees with more satisfaction will produce better work outcomes.

Practically, Borneo Post (2013), reported that there were 1248 incidents in the workplace from the 10 sectors had been reported in May 2013 from the report of Occupational Safety and Health Ministry of Human Resource. It is highlighted in Borneo Post (2013) that the manufacturing sector is among the highest contributor to the total number of accidents reported up to May 2013 (774 cases and 30 dead cases). BERNAMA (2012) reported that the incident happened on 16 June 2012 at petroleum terminal in Kuala Lumpur because of the employer's failure to observe the employee causing the employee to fall into the sea and drowned. Based on the annual report of Occupational Safety and Health Ministry of Human Resource (Official Portal, 2015), the statistic showed that the number of incidents occurred in the workplace had increased every year. There were 1493 incidents in 2011, 1649 incidents in 2012, 1700 incidents in 2013 and 1723 incidents in 2014 that happened in the manufacturing sector. From the above statement, it is important to examine the important role played by safety climate at workplace towards the safety performance.

According to the theoretical, empirical and practical discussion, it indicates that there is a need to conduct the study. In addition, the safety climate study is more in the field of construction industries but less in the output industries. Therefore, the research question which is arisen for this study is as follows:

Is there any relationship between safety climate factors and safety performance?

\section{Objectives}

The general objective of this study is to identify the relationship between safety climate factors and safety performance. There are several specific objectives of this study as follow:

- To determine the relationship between the positive workforce safety attitude and safety performance.

- To determine the relationship between the acceptance of safety rules and regulation and safety performance.

- To determine the relationship between the reasonable production schedule and safety performance.

\section{LITERATURE REVIEW}

The theories and model that have relation to the study are a social capital theory, domino Heinrich theory, and model of human factors investigation tool (HFIT). The social capital theory discusses the series of social dimension that influences the perception and behavior of an individual in the workplace. These dimensions involve the employees' direct supervision, the behavior of the colleague, the policies, and practice of managerial. These dimensions can change the behavior of people and their perception about the workplace (Coleman, 1988). The role of the manager in training the employee to achieve positive safety workplace has brought the effect on the perception of safety climate. Besides that, understanding own is responsibility in the workplace is also important to ensure the safety in the workplace. This social capital theory is related to the independent variables in this study. The acceptance of rules and regulation requires the worker's own responsibility to observe all the rules set by the organization. The manager's role in the organization is also important to enhance the positive workforce attitude among the employees. Based on this explanation, this theory can be used to explain this study.

Domino Heinrich Theory reported that accidents happen in the workplace are due to the main factors which are interrelated. The 5 main factors include injuries caused by accidents, accidents caused by the behaviors and unsafe condition, negative attitude, and behavior caused by the 
human weaknesses and human weaknesses caused by the personalities. Each domino has only one cause and the cause of the crash basis in this model is the social environment, individual's personality or bad characteristic among the worker in the company. The bad characteristic and personality lead to the unsafe condition in the workplace. Generally, Domino Heinrich Theory provides a better understanding of the independent variable in this study. Positive workforce attitude and the production time are easily influenced by the social environment in the workplace. People working in a negative social environment tend to make mistake due to the unsafe action. This will cause accidents and injuries in the workplace. The more increase is the number of accidents in the workplace, the more negative is the safety climate and safety performance in the workplace. Hence, this theory is helpful in order to investigate the relationship between safety climate factors and safety performance in the workplace.

HFIT are proposed by Gorden et al. (2005) to analyze the causes of the accident in the organization. This model is one of the systematic methods for collecting data about the impact of accidents caused by human factors. The interaction between human factors and accident are considered into several series which include wrong acts that occurred immediately before the accident, repeated accident because the previous accident has not been prevented vice versa, awareness of the situation, and dangerous in the workplace. This theory can be applied in this study. Based on this theory, the cause of the accident can represent the safety climate factor in the workplace. The accidents that occur due to the same cause implies that the safety climate in that aspect is still negative.

Research shows that there were a few studies about the safety climate in the workplace that involved the responsibility of top managers (Wu et al., 2010) and supervisors (Kapp, 2012). The more effective in managing safety are decentralized safety management structure and participative management style of supervisors. Lingard et al., (2010) conducted a study the safety climate of subcontractors who worked in a hospital project in Australia. The results showed that worker's perception of supervisor safety was a significant predictor of the subcontracting organizations' lost-time and medical treatment injuries. The findings suggested that supervisory personnel play an essential role in safety management.

Hon, et al., (2014) conducted the study of the safety climate and injury occurrence of repair, maintenance, minor alteration and addition work. The findings show that the safety of workers will increase significantly when the employers force the employees to abide safety rules and safety work procedure. Different levels of workers have different perception of safety climate factors issues. The workers' perception of the causes of accidents are safety attitude and safety rules and regulation. While reasonable production schedule is the primary predictor for the supervisor. Studies by Bergheim et al., (2013) indicate that psychological capital is positively correlated with safety climate in the maritime industry. The officer's perceptions of safety climate are more positive than the non-officer. This is in line with earlier findings from other industries indicating that leaders are more attuned to organizational priorities, such as compliance with safety regulation in safety-critical organization. The results also showed that people who are satisfied with their work have more positive impressions of safety.

The safety climate research have a positive link with the safety performance in the construction industries. The framework research of safety climate and safety performance in multi-story building at Pakistan by Zahoor, et al., (2015) indicate that safety performance was greatly influenced by the safety climate. The higher the safety climate, the higher is the safety management. This will bring to higher safety knowledge and able to follow all the safety rules and regulation in the organizational. In order to avoid any accidents in the workplace, the important element that should have a link between employers and employees, employees and work colleague is a trust (Avram, et al., 2014). The value of trust among each other encourages the workers to make the report honestly about the mistakes of safety procedures during the job so that the organization can find ways to solve the problem with safety management to avoid further accidents.

\section{Research Design And Sample}

Quantitative approach has used in this study. The advantages of quantitative approach are simpler and cheaper. Besides that, a quantitative approach also enables the researcher to analyze more than one variable at one time (Mulder and Yaar, 2007). This approach is still being chosen because the researchers want to investigate more than one variable in the study by using a simpler way and lower cost to conduct the research. The technique used in this study is questionnaires and is a preformatted set of questions designed (Ahmad et al. 2014). The population consists of the employees who work in the operational department at the cold storage company. 150 people were chosen randomly from this department. The researcher uses the formula proposed by Churchil and Brown (2004) to calculate the sample size.

\section{Data Analysis}

The collected data were analyzed using the SPSS version 22. The inferential statistic was used for making inference about the information gained from the population (Mendenhall et al. 2013). Pearson Correlation is used to test the relationship between the independent variables and dependent variable. According to Evan (1996), the degree of relationship between independent variables and dependent variable can be measured by the value of -1 and +1 . 


\section{Respondents Characteristics}

Overall, there are more male respondents (58\%) compared to female respondents (42\%). Majority of the workers (54\%) are at the age of 20-30 years old, followed by the age of 3140 years old ( $37.33 \%)$ and the least is the workers at the age of $41-50$ years old which is only $8.67 \%$. Malay workers occupied the highest percentage which is $46.67 \%$, the second in rank which is $31.33 \%$ is represented by other races such as Iban, Bidayuh, and Melanau while Chinese workers occupied the lowest percentage which is $22 \%$. For the highest academic qualification of respondents, most of the respondents are SPM holders $(80.67 \%)$ while the least is form degree holders $(0.67 \%)$. The second and third are STPM holders (14\%) and diploma holders (4.67\%). For the length of services majority of the workers have worked between 2 to 5 years (43.33\%), followed by the more than 10 years (21.33), 6 to 10 years (19.33\%) and less than 2 years $(16 \%)$.

\section{RESULTS AND DISCUSSION}

$\mathrm{H}_{\mathrm{a}}$ : There is a significant relationship between positive workforce safety attitude and safety performance

Table 1: Correlation between positive workforce safety attitude and safety performance

\begin{tabular}{lcc}
\hline Variables & 1 & 2 \\
\hline (1)Positive workforce safety attitude & 1 & \\
(2)Safety performance & & $.731^{* *}$ \\
\hline$* *$ Correlation is significance at the 0.01 level (2-tailed)
\end{tabular}

Table 1 show the value of coefficient $r=0.731$ and $p=0.000$. This indicates that there is a strong positive relationship between positive workforce safety attitude and safety performance due to $p<0.00$ and the $r$ value is in the area of $0.60-0.79$. The result shows that there is the significant relationship between the positive workforce safety attitude and safety performance. The hypothesis is accepted. This means that if the positive workforce safety attitude of the worker's increases, the safety performance is at a higher level. The result shows that there is a strong significant relationship between the workforce attitude and safety performance. This means that every employee in cold storage company needs to have the positive attitude in order to increase the safety climate and safety performance in their workplace.

The Domino Heinrich Theory (Heinrich, 1929) can be used to explain the results more clearly. Based on this theory, there were five main factors that are inter-related can lead to the occurrence of accidents, including injuries caused by accidents, behavior, unsafe condition, negative attitude and worker's personality. If the employees of the organization have the negative attitude while at work, the tendency for the accidents to occur is high. The higher the accidents rate, the lower is the safety climate and safety performance in the workplace. Based on the discussion above, it is important to have the positive workforce safety attitude in each employee.
Besides that, this finding can also be supported by the past research. According to Varonen and Mattila (2000), safety prevention is positively related to the accident rate if there are people with the negative attitude towards safety. This means that if the person has the positive workforce safety attitude, an accident will not happen easily. So, the accident rate will decrease and the safety performance of the organization will increase. This statement can be supported by the study carried out by Avram, et al., (2014) about the trust among the employer, employees, and working partners. Trustworthiness is important to make sure that the workers do not try to cover up the truth when making reports on the accidents or any problem related to the safety in the workplace. After receiving the report, the organization can find the solution to the problem. In order to have trust among all the employer, employees and colleagues, it is important that everyone has the positive workforce safety attitude. Based on the results above, there is a strong relationship between the positive workforce safety attitude and safety performance in the cold storage company. So, the employees need to have the good attitude to ensure that the safety performance in their workplace is in good condition. Based on the aspect of the practical discussion, the employers play an important role to supervise their workers to have the positive workforce safety attitude in the workplace. BERNAMA (2012) reported that the incidents were happened at petroleum terminal in Kuala Lumpur due to the lack attitude of an employee. The report also stated that the employer fails to observe the employee during at work. From this discussion, it shows that the positive workforce safety attitude is an important factor to have better safety performance.

$\mathrm{H}_{\mathrm{a} 2}$ : There is a significant relationship between acceptance of safety rules and regulation and safety performance

Table 2: Correlation between Acceptance of Safety Rules and Regulation and Safety Performance

\begin{tabular}{lll}
\hline Variables & 1 & 2 \\
\hline (1) Acceptance of safety rules and regulation & 1 &
\end{tabular}
$\frac{\text { (2)Safety performance }}{* * \text {. Correlation is significance at the } 0.01 \text { level (2-tailed) }}$

Based on the table above, the hypothesis for safety performance $\mathrm{H}_{\mathrm{a} 2}$ is fail to reject. Table 2 show the value of coefficient $r=0.274$ and $p=0.001$. This indicate that there is a weak relationship between acceptance of safety rules and regulation and safety performance due to $\mathrm{p}<0.00$ and the $r$ value is in the area of $0.20-0.39$. The result shows that there is a significant relationship between (acceptance of safety rules and regulation with safety performance) and the hypothesis is accepted. This means that if the acceptance of safety rules and regulations among the workers is high, the safety performance of the organization will also increase. Previous research, they stated that the safety rules and regulation may influence the level of work injuries and accidents. The probability to occur an accident was high if the employees were unable or unwilling to 
follow the safety rules and regulations during at work. This statement can be supported by the previous research of Hon, et al., (2014) about the safety climate and injury occurrence of repair, maintenance, minor alteration and addition work. The findings show that the safety of workers will increase significantly when the employers force their employees to abide by all the safety rules and regulation in the workplace. Based on the discussion above, it shows that the findings of the study match the results of previous research.

The findings of the research can also be explained based on the theoretical discussion. Looking at the model of HFIT proposed by Gorden et. al. (2005), there was the interaction between the human factor and the accidents. This interaction is separated into series which include the wrong acts that occurred immediately before accident, repeated accident because not following the rules, the awareness of situation and dangers in the workplace. The series of the repeated accident because of not following the rules can be used to explain the finding of the study. If the employee refuses to follow the safety rules and regulation, then accidents may also happen again and again. In order to have better safety climate and safety performance in the workplace, the employees need to follow all the safety rules and regulation in whatever situation. Besides that, the report from BERNAMA (2012) can also be used to explain the finding of this study. The incident that happened on 16 June 2012 at terminal Kuala Lumpur was because there was nobody to remind the workers to follow the actual safety rules and regulation. This had caused the employee to fall into the sea and drowned. This accident has proved that safety rules and regulation is important in every place. Based on the discussion that had been made by the researcher, it can be concluded that the empirical, theoretical and practical can prove and strengthen the finding for the Ha2. Thus, both the discussion supports the research findings that there is a significant relationship between acceptance of safety rules and regulation and safety performance.

$\mathrm{H}_{\mathrm{a} 3}$ : There is a significant relationship between reasonable production schedule and safety performance

Table 3: Correlation between Reasonable Production Schedule and Safety Performance

\begin{tabular}{llc}
\hline Variables & 1 & 2 \\
\hline (1) Reasonable production schedule & 1 & \\
(2) Safety performance & & -.05 \\
\hline$p$-value $=.547$ & &
\end{tabular}

$p$-value $=.547$

Based on the table above, the hypothesis for safety performance $\mathrm{H}_{a}$ is rejected. Table 3 shows the value of coefficient $r=-.05, p$-value $=.547$. This indicates that there is no relationship between reasonable production schedule and safety performance due to no correlation value and the $r$-value is negative. The result shows that there is no relationship between reasonable production schedule and safety performance. So, the hypothesis is rejected. This means that if the production schedule increases, it will not bring any effect to the safety performance among the workers in the organization. According to Domino Heinrich Theory, the production time can easily to influence the social environment in the workplace. A large amount of production schedule can bring in the negative social environment to the organization. In turn, this negative social environment will lead to the occurrence of incidents in the workplace. Besides that, the model of HFIT can also be used to explain these results. Based on this theory, the accidents happen is separated into several series. If the production schedule leads to the wrong acts of the employees, then the workplace is dangerous and accidents may occur. While if the production schedule does not lead to the wrong act of the employees, then the workplace is in the safe condition and the safety performance is at a high level.

From the empirical point of view, Hon, et al., (2014) disagree that the production schedule will cause any incidents among the workers in the workplace. They stated that the production schedule is the predictor for the supervisor and not the workers. The production schedule is adjusted by the supervisor. Thus, this view can support the reason why the finding of the study for $\mathrm{Ha} 3$ is rejected. In conclusion, the research findings for this part is there is no significant relationship between reasonable production schedule and safety performance among the workers.

\section{IMPLICATION OF STUDY}

The three aspects of implication which are the implication of body knowledge, implication of organization and implication of employees will be discussed in this part. The implication towards the body of knowledge in this study can provide the holistic view regarding how the different safety climates influence the safety performance of the workers in the workplace. The researcher and the public can understand better the relationship between safety climate factors and safety performance. Besides that, this study is conducted to enhance the previous literature on safety climate factors towards the safety performance. This study will contribute and explore more knowledge about the positive workforce safety attitude, safety rules and regulation, reasonable production schedule of the company and the relationship between demographic variables and the safety performance. It can also widen the knowledge of researcher and the public on the safety climate in the workplace and safety performance. It can make both the researcher and the public see clearer the relationship between safety climate factors and safety performance.

This study also helps the chosen organization which is cold storage industries factory to understand more about the safety climate in the company. The final results of this study can let the practitioners know the relationship between safety climate factors and safety job performance among their workers. Based on this results, the company can improve the safety climate and indirectly can also improve the workers' safety job performance. While for the employees, this study can reveal the importance of safety 
climate in their work to make sure that they can perform better in their job. From this study, they will be able to know which factor of safety climate will affect their performance.

This study brings the implication also towards organization on how safety climate factors can affect the safety performance in the workplace. Based on this study, it can raise the awareness of the organization of the importance of safety in the organization. Besides that, the organization can improve their safety performance by reorganizing the strategy of the organization according to the findings of the study. For example, provide safety training to their employees to increase the employees' safety attitude because there is a significant relationship between positive workforce safety attitude and safety climate. This study can also provide an effective way to the organization to improve the safety performance among their workers. The implication towards the employees is the employees can clearly know what safety climate factors can influence the safety performance in their workplace. If the employees are clear about all these, the employees sure will follow the entire safety requirement in the organization. This study can reveal the importance of safety climate in their work to make sure that they can perform better in their job.

\section{LIMITATION OF STUDY}

This study was conducted in only one organization which is Cold Storage Company. The questionnaires were distributed to the workers who work under the operational department. In this study, only one department of an organization was chosen. Therefore, the data was limited to see the overall safety climate and safety performance among the workers. Besides that, the researcher only focused on the relationship between three safety climate factors with safety performance which are positive workforce safety attitude, the acceptance of safety rules and regulations and reasonable production schedule. So, the limitation of this study is there may have other safety climate factors that can influence the safety performance of the workers in the workplace. Last but not least, the researcher only used the quantitative approach to collect all the research data. In order to get the more accurate result, it is possible to conduct the research using quantitative approach and qualitative approach.

\section{RECOMMENDATIONS}

The recommendation for the organization is the organization need to provide the safety training to their employees. This training is important to introduce and to show to the employees how important is the safety in the workplace. The organization needs to always remember their workers regarding the safety in the workplace. This is because the safety is the main thing in doing every kind of work, safety is always first. Besides that, the organization has the responsibility to ensure the safety of each of their employees. So, the training for every employee before they start to work is needed to maintain the safety performance in the workplace.The recommendation for the workers is the workers must always have good behavior and attitude all the time while they are in the workplace. This is because the best behavior and attitude can help them to avoid accidents to occur during the operation time. The good behavior and attitude will enable them to always concentrate and know what they need to do when they are doing dangerous thing such as using the risky machines. Besides that, the workers should follow the right procedure in doing everything. Although they are rushing to produce a large amount of product, they should not neglect any rules and regulation. They need to follow the right step that had been set in the rules and regulation of their organization. This is important to provide a better safety climate and improve the safety performance of the organization.

The recommendation for future research is to determine other safety climate factors that can influence the safety performance of the workers in the workplace. This is because there will be another safety climate that can influence the safety performance of the organization. Besides that, this study was conducted only at one of the production lines. So, the future research can conduct the study on safety climate in other places with different safety climate factors. Another recommendation for the future researcher is the future researcher can conduct the study by using a qualitative approach. This is because this study uses an only quantitative approach which is just distributing the questionnaire to the respondents. By using the qualitative approach, the research can collect more information and feedback from the informants. Therefore, the qualitative approach can help the researcher to gain more understanding of the study.

\section{CONCLUSION}

Generally, this study is to determine the relationship between the safety climate factors and safety performance among the workers. Based on the results obtained, it is cleared that there is a strong significant relationship between positive workforce safety attitude and safety performance but there is a weak relationship between acceptance of safety rules and regulation with the safety performance. The third hypothesis is rejected because the result shows that there is no relationship between reasonable production schedule and safety performance. This study is important to the organization because safety climate is an important factor to ensure the safety performance in the workplace.

\section{REFERENCES}

Ahmad, R. Usop, H. Ismail A. Bujang, S. and Abu Mansor, N. H., (2014). Conducting research in social sciences and management studies: Practical and a step-by-step guide. Malaysia: RS Publishing House.

Avram, E., Ionescu, D., and Mincu, C. (2014). Perceived safety climate and organizational trust: The Mediator roles of satisfaction. Procedia Social and Behavioural Science, 187, 679684 . 
Bergheim, K., Nielsen, M., Mearns, K., and Eid, J. (2013). The relationship between psychological capital, job satisfaction and safety perceptions in the maritime industry. Safety Science, 74, 27-36.

BERNAMA (4 August 2012). "Kurang langkah keselamatan punca kematian di jeti terminal petroleum".

Bigelow, K.C. (2011). Improving safety climate in organizational. London: Sage.

Borneo Post (10 October 2013). DOSH records 1248 workplace accidents in 10 sectors.

Bryman, A. (1988). Quantity and Quality in Social Research. London: Routledge.

Cheyne, A., Oliver, A., Tomas, J., and Cox, S. (2002). The architecture of employee attitudes to safety in the manufacturing sector. Personal Review, 31(6), 649-670.

Churchil, W., and Brown, J.K,. (2004). Research Method- guidelines for postgraduates. London, Arnold.

Coleman, J. (1998). Social capital in the creation of human capital. American Journal of Sociology, 94, 95-120.

Dane, M. (1990). The good research guide. Buckingham, Open University Press.

Dole, C. and Schoeder, R.G. (2001). The impact of various factors on the personality, job satisfaction and turnover intentions of professional accountants. Managerial Auditing Journal, 16(4), pp. 234-245.

Dov, E. (2010). Organizational culture and organizational safety. San Francisco, CA.

Evan, Y. P. (1996). Statistical analysis for education and psychology researchers, London, Falmer.

Frank, H., and Ronald, M. (2010). Construction plant (Limited edition), Granada.

Glendon, A.I., and Mckenna, E.F., (2000). Human safety and risk management. London: Routledge.

Gorden, F., Ken, H., and Fance, B. (2005). The perceived effect of safety climate on occupational accidents. Safety Science, 36(2), 15-27.

Hon, C., Hinze, J., and Chan, A. (2014). Safety climate and injury occurrence of repair, maintenance, minor alteration and addition works. Facilities, 32 (5), 188-207.

Kamarulzaman, N., Saleh, A., Hashim, S., Hashim, H., and AbdulGhani, A. (2011). An overview of the influence of physical office environment towards the employee. Procedia Engineering, 20, 262-268.
Kapp, E.A. (2012). The influence of supervisor leadership practices and perceived group safety climate on employee safety performance. Safety Sciences, 50 (4), 1119-1124.

Lingard, H., Cooke, T., and Blisman, N. (2010). Safety climate in the condition of construction subcontracting: a multi-level analysis. Construction Management and Economics, 28(8), 813-825.

Lingard, H., Wakefield, R., and Cashin, P. (2011). The development and testing of a hierarchical measure of project OHS performance. Engineering, Construction, and Architectural Management, 18(1), 30-49.

Mearns, K., Whitaker, S.M., and Flin, R. (2003). Safety climate, safety management practice and safety performance in offshore environments. Safety Science, 41(8), 641-680.

Mendenhall, W., Beaver, R. J., and Beaver, B.M. (2013). Introduction to probability and statistic (14th ed). Boston: Brooks / Cole, Cengage Learning.

Mulder, S. and Yaar, Z. (2007). The user is always right: A practical guide to creating and using personas for the web. Berkeley: New Riders.

Official Portal, Occupational Safety and Health Ministry of Human Resource. (2015) Retrieved on 8 October from http:/ / www.dosh.gov.my.

Omogoroye, O., and Oke, S. (2007). A safety control model for an offshore oil platform. Disaster Prevention and Management, 16 (4), 588-610.

Tharaldsen, J.E., Olsen, E. and Rundmo, T. (2008). A longitudinal study of safety climate on the Norwegian continental shelf. Safety Science, 46(3), 427-439.

Varonen, U., and Mattila, M. (2000). The safety climate and its relationship to safety practices, the safety of the work environment and occupational accidents in eight woodprocessing companies. Accidents Analysis and Prevention, 32, 761-769.

Wu, T.C., Lin, C.W. and Shiau, S.Y. (2010). Predicting safety culture: the roles of employer, operations manager and safety professional. Journal of Safety Research, 41(5), 423-431.

Zahoor, H., Chan, A., Utama, W., and Gao, R. (2015). A research framework for investigating the relationship between safety climate and safety performance in the construction of multistory buildings in Pakistan. Procedia Engineering, 118, 581-589.

Zin, S., and Ismail, F. (2012). Employers' behavioral safety compliance factors toward occupational, safety and health improvement in the construction industry. Procedia - Social and Behavioral Sciences, 36, 742-751

$--0--$ 
How to Cite: Ahmad, R., Ching, C., Bandar, N., Hamidi, H., Shaminan, A., \& Siong, H. (2018). Relationship between Safety Climate Factors and Safety Performance among the Workers in Cold Storage Industries. American Journal of Trade and Policy, 5(3), 85-92.

\section{SOCIAL SCIENCE RESEARCH NETWORK}

2171 Monroe Avenue, Suite 203, Rochester, NY 14618, USA

http://www.ssrn.com/en/

SSRN Link: http://www.ssrn.com/link/American-Journal-Trade-Policy.html 